\title{
Conceptualization and Reconceptualization of Spatial Relations
}

\author{
Svetlana Bogdanova \\ Irkutsk State Linguistic University, Irkutsk, Russia
}

\begin{abstract}
The study focuses on the phenomenon of reconceptualization of spatial relations reflected mostly lexically. It is hypothesized that in some cases, different spatial relations can be reconceptualized. It often happens when the situation or event is perceived from different points of view as a complex. The analysis is based on concrete linguistic material, with an emphasis on English phrasal verbs with spatial particles such as dig out, sink down. Two concepts play an essential role in the approach at hand: (1) Conceptualization is based on the bodily experience and depends on the observer's point of view; and (2) Spatial relations, which have been long known to constitute one of the bases of human cognition, structure a lot of conceptual domains. The method of conceptual analysis has been chosen as the leading method of this study. In the paper, we show 10 conceptual domains structured on the basis of spatial associations. Their common features can be traced by analyzing spatial particles as well as their groupings. In fact, spatial particles can practically lose their unique characteristics and start being treated as similar. The majority of conceptual domains are marked by spatial particles with the rethought meanings, so we can expect that the particles with the largest number of rethought meanings will be used more often than the others. Thus, it has been proved that the postpositions out and down are used in a number of groupings to mark different conceptual domains.
\end{abstract}

Keywords: conceptualization, reconceptualization, spatial relations, phrasal verbs, particles

\section{Introduction}

Modern cognitivists agree that linguistic knowledge is represented in the mind, that it is somehow perceived and used, and there are some relations of this knowledge to other components of cognition. The paper aims at the investigation of spatial conceptualization and reconceptualization of inner and outer world by studying their linguistic representations. According to the cognitive approach, linguistic entities and constructions possess their meanings owing to the reference to human experience, different levels of encyclopedic knowledge, and conceptual worldview. English phrasal verbs demonstrate that most of the objects and phenomena are conceptualized spatially, and the particles can characterize them as perceived from the point of view of some definite spatial dimension. It makes a phrasal verb an exceptionally convenient object for our investigation.

\section{Conceptualization}

Every language has a set of means to characterize spatial relations. It is universal. However, languages of the world differ widely in their treatment of space (Miller \& Johnson-Laird, 1976); in many languages, the means to express them vary. Spatial relations are conceptualized as most important for human beings (Bennett,

Svetlana Bogdanova, professor, Ph.D., Department of Linguistics and Educational Technologies, Irkutsk State Linguistic University. 
1975; Vater, 1991; Lindner, 1981). Orientation schemas, such as "container" and "source-path-goal", model human conceptualization of different spatial relations (Lakoff \& Johnson, 1980; Svorou, 1994; Lee, 2004; Kubryakova, 2004). Prototypical spatial relations presented in the English language can be divided into several "cells" (Talmy, 1983). The combinations of these "cells" can render all the spatial relations, even the most complicated, between real objects as well as abstract ones. As our conceptual system is based on associations and comparisons, in many cases, it is impossible to conceptualize a particular event from the point of view of only one spatial relation. If we consider, for example, the situation of sinking, we notice both containment and downward movement in the vertical plane (see Example (1)).

Example (1) She closed her eyes, let herself sink down into her imagination, remembering, remembering... (Bradford).

A limited number of spatial elements in any language, caused by the peculiarities of the human perception of space, help linguists to trace their groupings and define the main directions of shifts of meanings. Spatial elements have a tendency to develop metaphorical meanings, extending their direct spatial meanings. Thus, spatial elements acquire the ability for nominating some other spheres of activities, including mental activity. Human comprehension of complicated and abstract entities and events of the surrounding world is grounded mainly on basic spatial dimensions. Their number is limited as well as the number of denoting them spatial adverbs, prepositions, prefixes, particles, etc.. These elements can be used in several conceptual domains in their direct as well as metaphorical meanings (see Table 1).

Table 1

Conceptual Domains and the Phrasal Verbs (Verbs + Particles) Denoting Them

\begin{tabular}{|l|l|l|l|}
\hline No. & Conceptual domains & Verbs & Groupings of particles \\
\hline 1 & Volume of sound & cry, shout, speak & out, up \\
\hline 2 & Making a boundary & barricade, cordon, fence, hedge, hem, keep, rail, seal, tape, wall, wire & in, off, out \\
\hline 3 & Cleanness & clean, clear, freshen, scrub, tidy & away, down, off, out, up \\
\hline 4 & Spreading & spread, stretch, widen & ahead (forth), off, out \\
\hline 5 & $\begin{array}{l}\text { Negative: tiredness } \\
\text { defeating } \\
\text { elimination } \\
\text { cooling }\end{array}$ & $\begin{array}{l}\text { tire, wash, wear, wipe; } \\
\text { fight, knock; } \\
\text { gun, finish, kill, shoot, take; } \\
\text { cool }\end{array}$ & down, off, out \\
\hline 6 & Calmness & calm, cool, quiet/quieten, settle, simmer, sober, steady, talk & down, off \\
\hline 7 & Depth & dig, dive, drink, drown, sink & in, down \\
\hline 8 & Searching and finding & $\begin{array}{l}\text { dig, ferret, fish, hunt, mouse, nose, root, scout, search, seek, smell, } \\
\text { sniff, spade }\end{array}$ & around, out, up \\
\hline 9 & Tracing & hunt, trace, track, trail & down, out \\
\hline 10 & Switching on/off & flash, flick, flicker, put, snap, switch, touch, turn & on, out, off \\
\hline
\end{tabular}

Spatial adverbial particles, such as up, down (indicating vertical dimension), in, out (indicating the dimension of containment), on, off (indicating contiguity), can acquire figurative meanings and in most cases the oppositions will be observed. If the direct meanings of particles can still be traced, we can speak about metaphorical mappings, which give rise to polysemy. However, sometimes the extension of meanings of spatial particles results in forming a new meaning, belonging to a different conceptual domain.

\section{Reconceptualization}

The analysis of the examples of spatial conceptualization of different events which are represented in the 
system of English phrasal verbs proved that it is possible to differentiate two levels of knowledge structuring: conceptualization and reconceptualization. In the process of conceptualization, direct spatial meanings are formed with the possibility of their further metaphorization. The oppositions of spatial particles in English are observed: up-down, ahead-back, in-out, and on-off. They can be compared with the oppositions of spatial

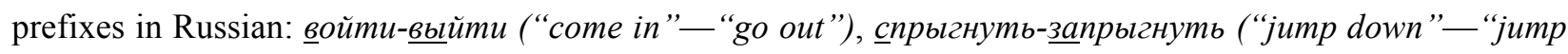
up”), etc.. Some spatial relations are reconceptualized when they are involved in perceiving complex situations or events. In fact, spatial particles can partially lose their unique characteristics and start being treated as similar.

Thus, in some contexts the particles out, down, and off can have rather close meanings and together they can characterize the conceptual domains of "negativeness", "tiredness", and "cooling" (see Example (2)).

Example (2) fight down - fight out; wear out-wear down-wear off; cool down-cool off—cool out, etc.

It often happens when the situation or event is perceived from different points of view as a complex. The same scene can be represented in a number of ways, because "what we see is mediated by the conceptual system" (Tyler \& Evans, 2003, p. 21). For example, if we consider the situation of tiredness we can conceptualize it in some different ways:

(1) Tiredness can be compared to the state of a thing which was very often washed and as a result lost its qualities (see Example (3)):

Example (3) I was feeling pretty washed out.

(2) It can be compared to the state of a thing which was worn for a very long time and became old and shabby (see Example (4)):

Example (4) The chase was beginning to wear him down.

In the process of reconceptualization particles in metaphorical (extended) meanings combine into groupings. The peripheral meaning of one spatial particle can be connected with the peripheral meaning of the other spatial particle, as a result of this merging, there appears a grouping of their metaphorical meanings, which is a productive derivational model in English. Thus, treating the state of "tiredness", one person would conceptualize it as going down, which is associated with going to something worse (Bad Is Down) (Lakoff \& Johnson, 1980), the other person would conceptualize it as going out of the normal state, treated as an abstract "container". The third person would treat the same situation as separating from the boundary dividing the good state from the bad one (wear down-wear out-wear off). The conceptual domain of "negativeness" is represented in a number of phrasal verbs of different lexical-semantic groups. Phrasal verbs cool down, cool off, and cool out show different degrees of the process of cooling, up to full negation (see Examples (5)-(7)).

Example (5) For the rest, Toby advised me to cool down, bide my time, and act as if nothing had happened (Le Carré).

Example (6) We'll go outside and cool off (Crichton).

Example (7) They cooled out the power reactor (King).

The same phenomenon can be observed in the Russian language in the system of verbs with spatial prefixes. In some contexts, different spatial prefixes have practically the same meaning (see Example (8)).

Example (8) rus. обогнать—-ерегнать (“come first”), выжидать-пережидать (“wait for some time”), побить-избить (“beat smb ир”), уронить-выронить (“drop smth”), colloq. утворить-вытворить-натворить (“do smth wrong”), выгнать-прогнать (“send off”), въехать-заехать (“drive into"), etc. 
The groupings of spatial elements reflect the processes of conceptualization and reconceptualization of spatial relations. Phrasal verbs in English and prepositional verbs in Russian illustrate the peculiarities of the linguistic categorization of the world, caused by the human cognitive activity (Bogdanova, 2010).

\section{Classification of Reconceptualization of Spatial Relations}

It is stated in the paper that the reconceptualization of spatial relations is the rethinking of their presentations in the human mind. This rethinking of the presentations of spatial relations, which is reflected in the system of English phrasal verbs, can run in different directions. So, the reconceptualization of spatial relations can be classified according to: (1) the degree of rethinking; and (2) the direction of the meaning transfer.

According to the first classification, the reconceptualization of spatial relations can be zero, partial, and complete.

Zero reconceptualization represents spatial relations between the objects of the world that can be perceived (in English, the particle away in He went away immediately expresses the direction of motion).

Partial reconceptualization affects the metaphorically or metonymically rethought spatial relations. The spatial component can still be singled out within the concept (in English the particle down in You should cool down, let's make a stroll expresses the metaphorically rethought direction from the overexcited state to the normal one).

Complete reconceptualization, however, often leads to breaking down and wiping off the boundaries between the presentations of different spatial relations. As a result of these processes, the meanings of spatial particles within phrasal verbs become more and more abstract, and the fact of desemantization of such spatial particles can be stated (in English, the particle up in Give up smoking expresses the completion of action, but not the upward direction).

According to the second classification, the reconceptualization of spatial relations can lead into different abstract areas, such as temporal, aspectual, social, etc.

(1) In some cases, the reconceptualization of spatial relations can be directed into the area of temporal relations. It is represented in the English language by the usage of phrasal verbs with the particle on (Go on, please), which used to have spatial meaning, and the particle away in the constructions with the direct object of time period (We talked the night away). Phrasal verbs with the particle away represent the spatial relation of extent that was reconceptualized in the direction of the area of temporal relations.

(2) The reconceptualization of spatial relations in the direction of the area of aspectual characteristics is mainly represented by phrasal verbs with the particles with a great number of extended meanings: up, out, down, off, away, and some others. In modern English with its analytical tendencies, it can be explained by the lack of subtle aspectual meanings, which in many languages, including Russian, can be expressed with the help of different affixes (делать-сделать). The number of phrasal verbs with the particles denoting the completion of action has been growing, and such particles can be used to specify the aspectual (mostly perfective) characteristics in the pairs eat-eat up, speak-speak out, etc.

(3) The reconceptualization of spatial relations in the direction of the sphere of abstract characteristics is based on spatial metaphors that pervade language; "they are necessary to conceptualizing various semantic domains, in particular abstract domains" (Herskovits, 1986, p. 1).

It must be noted that due to the constant changes of meaning and the growth of the number of contexts 
in which phrasal verbs with spatial particles can be used, there are no distinct boundaries between the mentioned types.

\section{Conceptual Domain “Depth”}

Among the number of orientation schemas, analyzed by Lakoff and Johnson (1980), two are presented in the system of English phrasal verbs - they are "source-path-goal" and "container". A lot of phenomena are conceptualized according to these schemas. In different combinations, they perform very important functions in conceptualization of reality. Alone or as a part of a combination, the mentioned schemas structure different conceptual domains, closely related to spatial relations. The example of their usage within one conceptual domain is the dimension of depth.

Unlike other spatial dimensions, such as verticality, horizontality (or laterality), depth represents a complex dimension, which is based on containment (or internality), but, except crossing the boundary, it presupposes some distance covered in the mentioned direction. H. H. Clark and E. V. Clark (1977) suggested that: "The dimensions languages pick out are far from arbitrary: They appear to be just those dimensions the human perceptual apparatus is turned to pick out" (p. 534). So, if there is no special spatial word to denote the dimension, it means that the dimension is not one of the most important. Still, it can participate in the processes of metaphorization according to the rules, accepted in the language for other dimensions.

Though we can speak about the "depth" of a cupboard, this dimension is primarily associated with the downward movement. Prototypically, the dimension of depth represents a combination of two spatial dimensions: verticality and containment. In the Russian language, the dimension of depth is represented in the conceptual domain "work": погрузиться в работу ("sink into work"), с головой уйти в работу ("sink with one's head into work"), and окунуться в работу ("dive into work"). Evidently, in these examples, there exists the indication to the direction downwards and the abstract "container" which are the necessary markers of the dimension of depth. We can remark here that the result of the actions denoted in the examples above is usually expected to be positive.

English phrasal verbs with the particles in and down (sink in, sink down, dig in, etc.) represent the dimension of depth. These particles can be treated as directive, they do not make an opposition and in many cases they just complement each other. Sometimes they can even act like synonyms.

Example (9) I dug in hard, trying to force the boat fast across the bay. "Don't pull down so deep" (Murray).

In Example (9), there are several lexical units, which represent the dimension of depth: phrasal verbs with the particles in and down, the adverb deep. It is important to point out that the verbs that nominate this dimension contain the semantic components "verticality" (sink, dig, and drown) and "containment" (sink, drink).

Example (10) She put down the receiver and sank down in an armchair (Christie).

Example (11) Drink in the air of freedom (Michener).

In Example (10), the phrasal verb sink down is used with the indication of the place, conceptualized as a "container". It is expressed by a combination of the noun armchair and the preposition into. In Example (11), the dimension of "verticality" is implied by our knowledge of the process of drinking, and the dimension of "containment" is represented by the phrasal verb drink in. The particle in is often used with the verb drink to denote abstract objects, such as ideas, music, etc.. In other cases, the verb drink adds the particle down. 


\section{Conceptual Domains “Searching and Finding” and “Tracing”}

The verbs dig, fish, and root denote such actions as getting down into the "container" and then coming back to the surface and higher (the surface plays the role of the boundary of the "container"). These verbs have peculiar characteristics when they are combined with the spatial particles around and out. Phrasal verbs dig around, root out, etc., characterize the conceptual domain "searching and finding", which is connected with the conceptual domain "depth" by family resemblance ties: Both conceptual domains can be denoted by the verb dig.

Prototypically, the grouping of the particles out and around shows the results of conceptualizing the situations of searching and finding from different points of view. This grouping helps to single out the verbs that can denote the domain. The particle out is traditionally associated with the "container" schema; the particle around is associated with circumference. Due to the fact that the spatial relations they represent are reconceptualized, these particles are usually used in their rethought meanings when, within a grouping, they represent the conceptual domain. Phrasal verbs dig around, dig out; fish around, fish out; mouse around, mouse out; nose around, nose out; root around, root out; scout around, scout out; and sniff around, sniff out also have metaphorical meanings, as in Examples (12)-(13):

Example (12) I managed to root out a copy of the document (OALDCE).

Example (13) He kept fishing around as if he were afraid he'd said too much the night before (Grisham).

The conceptual domain "searching and finding" seems to be rather close to the conceptual domain "tracing", as sometimes while searching somebody or something people or animals find traces and follow the track to find who or what they are looking for. The result of both actions (searching and tracing) can be marked by a phrasal verb with the particle out (nose out, hunt out) expressing the completion of action. Nevertheless, the two domains are different, due to their spatial conceptualization. The first one presupposes observation of a wide territory ("here and there, in every direction") and the result of this activity (taking something from the hidden "container"). The second domain presupposes following the tracks along the trajectory, which is often marked by a phrasal verb with the particle down.

Example (14) We tracked you down here from the address on your stationery (Klein).

Example (15) What he intended to hunt down, was a renegade, and loyal only to money (Forsyth).

\section{Conclusions}

The conceptual domains that are based on some spatial associations are very often interconnected. Their common features can be traced by analyzing spatial particles as well as their groupings, which reflect the processes of reconceptualization of spatial relations. The majority of conceptual domains are marked by spatial particles with the rethought meanings, so we can expect that the particles with the largest number of rethought meanings will be used more often than the others. In fact, it was proved that the postpositions out and down are used in a number of groupings to mark different conceptual domains.

However, the analysis of several conceptual domains showed not only their interconnection but also the difference between them caused by different spatial conceptualization of the events of the real world and other spheres of human activity, including mental. In the possibility to group particles from different dimensions into one conceptual domain, we see the result of the process of reconceptualization, that demonstrates the human ability to consider each event or process (especially abstract) from different angles and to treat different 
phenomena as similar to one another in some ways. It is really important to understand how humans conceptualize their experience, and what role in this process is given to their conception of spatial relations.

\section{References}

Bennett, D. C. (1975). Spatial and temporal uses of English prepositions: An essay in stratificational semantics. London: Longman.

Bogdanova, S. (2010). Projavlenija reconceptualizatzii prostranstvennykh otnoshenij v russkikh pristavochnykh i anglijskikh frazovykh glagolakh (Manifestation of reconceptualization of spatial relations in Russian prepositional and English phrasal verbs). Rossica Olomucensia, XLVIII(1), 23-26.

Clark, H. H., \& Clark, E. V. (1977). Psychology of language: An introduction to psycholinguistics. New York: Harcourt Brace Jovanovich.

Herskovits, A. (1986). Language and spatial cognition. Cambridge, UK: Cambridge University Press.

Kubryakova, E. S. (2004). Yazyk i znanie: na puti polucheniya znanij o yazyke (Language and knowledge: On the way of getting knowledge about the language). Moskva: Yazyki slavjanskoj kul'tury.

Lakoff, G., \& Johnson, M. (1980). Metaphors we live by. Chicago: Chicago University Press.

Lee, D. (2004). Cognitive linguistics: An introduction. Melbourne: Oxford University Press.

Lindner, S. (1981). A lexico-semantic analysis of verb-particle constructions with "up" and "out" (Ph.D. dissertation, University of California, San Diego).

Miller, G. A., \& Johnson-Laird, Ph. (1976). Language and perception. Cambridge, MA: Harvard University Press.

Svorou, S. (1994). The grammar of space. Amsterdam, Philadelphia: John Benjamins.

Talmy, L. (1983). How language structures space. Spatial orientation: Theory, research, and application (pp. 225-282). New York: Plenum Press.

Tyler, A., \& Evans, V. (2003). The semantics of English prepositions: Spatial scenes, embodied meaning and cognition. Cambridge: Cambridge University Press.

Vater, H. (1991). Einfuhrung in die Raum-Linguistic (Introduction to spatial linguistics). Hürth-Efferen: Gabel Verlag. 